\title{
The self-regulated learning of medical students in the clinical environment - a scoping review
}

\author{
Kenneth K. Cho*, Brahm Marjadi, Vicki Langendyk and Wendy Hu
}

\begin{abstract}
Background: Self-regulated learning is the individual's ability to effectively use various strategies to reach their learning goals. We conducted this scoping review to explore what has been found regarding self-regulated learning in the clinical environment and how this was measured.

Methods: Using Arksey and O'Malley's five-stage framework, we searched three medical and educational databases as well as Google Scholar for literature on the self-regulated learning of medical students in the clinical environment published between 1966 and February 2017. After results were screened and relevant studies were identified, the data was summarised and discursively reported.

Results: The search resulted in 911 articles, with 14 articles included in the scoping review after the inclusion criteria was applied. Self-regulated learning was explored in these studies in various ways including qualitative, quantitative and mixed methods. Three major findings were found: 1) levels of self-regulated learning change in the clinical environment, 2) self-regulated learning is associated with academic achievement, success in clinical skills and mental health and 3) various factors can support self-regulated learning levels in medical students.

Conclusions: Most of articles exploring the self-regulated learning of medical students during the clinical years have been published in the last 5 years, suggesting a growing interest in the area. Future research could explore the self-regulated learning levels of medical students during the clinical years using a longitudinal approach or through the use of novel qualitative approaches.
\end{abstract}

Keywords: Self-regulated learning, Clinical years, Clerkship, Scoping review

\section{Background}

Self-regulated learning (SRL) is the process where one is 'metacognitively, motivationally, and behaviourally proactive in the learning process' [1]. More specifically, selfregulated learners: (i) monitor their own progress towards self-set goals and are therefore able to reflect on the effectiveness of their learning approaches; (ii) tend to view the learning task as intrinsically interesting and worth-while, and have high levels of self-efficacy, and (iii) engage in and persist with learning behaviours that maximise the degree to which learning occurs [2]. The concept of SRL has been found to be relevant to high-school and university students, educators and policy makers $[3,4]$. In medical

\footnotetext{
* Correspondence: cho_kenneth@hotmail.com

School of Medicine, Western Sydney University, Campbelltown, NSW 2560, Australia
}

(c) The Author(s). 2017 Open Access This article is distributed under the terms of the Creative Commons Attribution 4.0 International License (http://creativecommons.org/licenses/by/4.0/), which permits unrestricted use, distribution, and reproduction in any medium, provided you give appropriate credit to the original author(s) and the source, provide a link to the Creative Commons license, and indicate if changes were made. The Creative Commons Public Domain Dedication waiver (http://creativecommons.org/publicdomain/zero/1.0/) applies to the data made available in this article, unless otherwise stated. learners, there has been a push for the development of SRL [5].

According to some theories, SRL can be categorized into four processes and four areas [6, 7]. The four processes of SRL are goalsetting, self-monitoring, feedback and control, whilst the four areas an individual can regulate in are cognition, motivation, behaviour and context $[6,7]$. The four processes and areas are illustrated in Table 1.

Despite the importance of SRL in medicine, and the significant influence of the environment on student learning [8], SRL cannot be assumed to automatically develop in the clinical learning environment. Medical students will often carry forward learning strategies that worked well in the preclinical years, often to their 
Table 1 Areas and processes of self-regulated learning $[6,7]$

\begin{tabular}{|c|c|c|c|c|}
\hline \multirow{2}{*}{$\begin{array}{l}\text { Self-regulated learning } \\
\text { processes }\end{array}$} & \multicolumn{4}{|l|}{ Areas for Self-regulation } \\
\hline & Cognition & Motivation/affect & Behaviour & Context/environment \\
\hline Goalsetting/forethought & $\begin{array}{l}\text { Setting a criterion to } \\
\text { compare progress with }\end{array}$ & $\begin{array}{l}\text { Setting a criterion to compare } \\
\text { progress with }\end{array}$ & $\begin{array}{l}\text { Setting a criterion to compare } \\
\text { progress with }\end{array}$ & $\begin{array}{l}\text { Setting a criterion to } \\
\text { compare with }\end{array}$ \\
\hline Self-monitoring & $\begin{array}{l}\text { A mechanism used to } \\
\text { keep track of their } \\
\text { thoughts }\end{array}$ & $\begin{array}{l}\text { A mechanism used to keep } \\
\text { track of their motivation }\end{array}$ & $\begin{array}{l}\text { A mechanism used to keep } \\
\text { track of their behaviour }\end{array}$ & $\begin{array}{l}\text { A mechanism used } \\
\text { to keep track of their } \\
\text { environment }\end{array}$ \\
\hline Feedback loop & $\begin{array}{l}\text { Cyclical processes to } \\
\text { monitor the } \\
\text { effectiveness of their } \\
\text { thoughts }\end{array}$ & $\begin{array}{l}\text { Cyclical processes to monitor } \\
\text { their motivational effectiveness }\end{array}$ & $\begin{array}{l}\text { Cyclical processes to monitor } \\
\text { the effectiveness of their } \\
\text { behaviour }\end{array}$ & $\begin{array}{l}\text { Cyclical processes to } \\
\text { monitor the } \\
\text { effectiveness of their } \\
\text { environment }\end{array}$ \\
\hline Control & $\begin{array}{l}\text { Selection and adaption } \\
\text { of cognitive strategies }\end{array}$ & $\begin{array}{l}\text { Selection and adaption of } \\
\text { strategies for managing } \\
\text { motivation and affect }\end{array}$ & $\begin{array}{l}\text { Deciding behavioural strategies } \\
\text { such as increasing or decreasing } \\
\text { effort, persisting or giving up }\end{array}$ & $\begin{array}{l}\text { Selection and adaption } \\
\text { of the best contexts fo } \\
\text { optimal learning }\end{array}$ \\
\hline
\end{tabular}

detriment $[9,10]$. Even after graduation, physicians may be quite unskilled at certain aspects of self-regulation, such as global self-assessment [11]. This review will explore what is already known about SRL in medical students during their rotations in the clinical environment.

Although scoping reviews are relatively new [12], they are becoming a more common method to provide an overview or "map" of the literature [13]. This is achieved by investigating the extent of existing research, summarising the findings of all relevant studies and identifying potential gaps in the field $[14,15]$. Our scoping review aims to accomplish all three of these reasons.

\section{Methods}

We used the five-stage framework proposed by Arksey and O'Malley in this scoping review which involves (1) identifying the research questions, (2) identifying relevant studies, (3) selecting the relevant studies, (4) charting the data, and (5) collating, summarising and reporting the results. As recommended by the five-stage framework, we did not use a quality appraisal tool for each study, but we followed the explicit process to ensure that our search was replicable, thus increasing the rigour of our findings [14].

\section{Stage one: identifying the research question}

The purpose of our review was to explore the SRL of medical students in the clinical environment. Our research questions were the following:

1. What has been found regarding the self-regulated learning of medical students in the clinical years of their program?

2. How has self-regulated learning in medical students in the clinical learning environment been measured?

\section{Stage two: identifying relevant studies}

A literature search was carried out to identify studies and reports between 1966 and February 2017 using the databases Medline (Ovid), ERIC, EBSCO and Google Scholar. The main search term "self-regulated learning" was combined with key terms and variants of "medical student", "medical school" and "medical education". The search identified 911 potential papers. The following criteria were used for the review and selection of the studies: available in English, focused on SRL in the medical clinical learning environment and relevant to the topic after review of abstracts. Articles investigating similar but different theories such as self-directed learning were not included due to conceptual differences [16, 17]. The first author $(\mathrm{KC})$ screened the titles and abstracts for relevance to the research questions, and 890 articles were excluded as they did not meet the inclusion criteria.

\section{Stage three: study selection}

The full texts of the remaining 21 articles were read by $\mathrm{KC}$ and 7 articles were excluded as the studies focused solely on non-clinical medical students. The reference lists of all selected publications were then hand searched for any additional relevant studies. Authors of key papers were also contacted for relevant reports or publications. Fourteen articles were selected for inclusion in the review (see Fig. 1).

\section{Stage four: data charting and collation}

The data extraction framework was developed by all authors and implemented by KC. Extracted data from the articles included: authors, date of publication, country of study, study population, study design, instrument used, a brief summary of the primary finding as well as areas and processes of SRL explored in the study. The findings are detailed in Table 2.

\section{Stage five: summarising and reporting the results}

The following Results section summarises and discursively reports the review findings. 


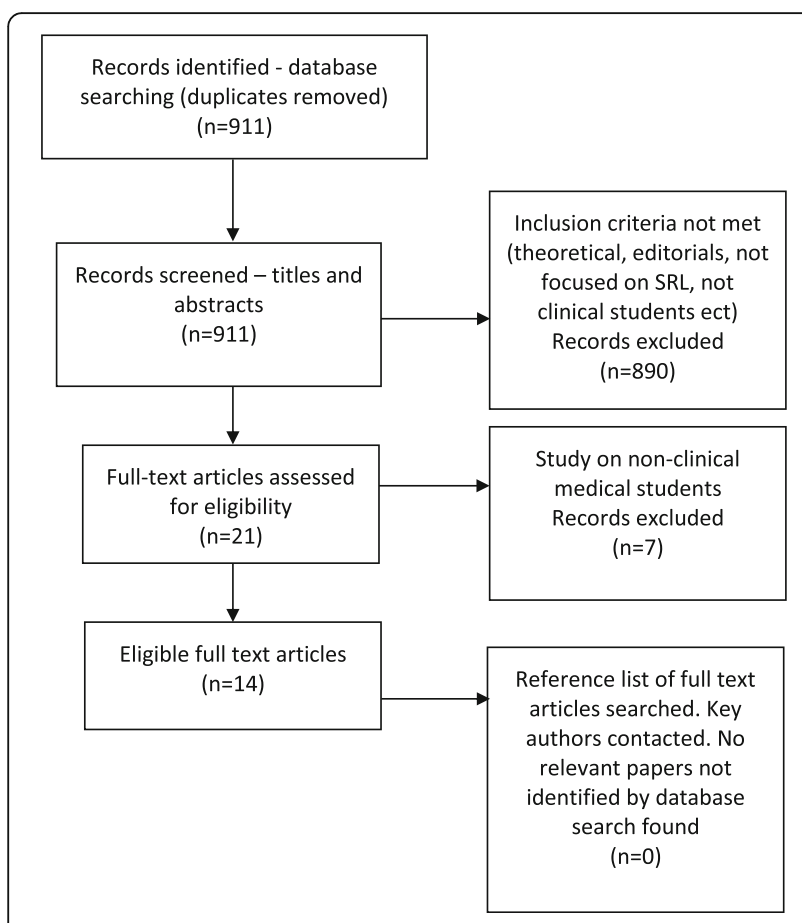

Fig. 1 Flowchart of Search Results. Figure 1 Flowchart of Search Results. A flowchart demonstrating this scoping review's search results

\section{Results}

What have studies found regarding self-regulated learning in the medical clinical years?

There were 3 major findings regarding SRL in the clinical years: 1) changes in SRL occur in the clinical learning environment, 2) higher levels of SRL are associated with higher academic achievement, more success in clinical skills and better mental health outcomes and 3) certain factors can influence SRL levels. These are further explained below.

\section{Changes in self-regulated learning occur in the clinical learning environment}

Three studies qualitatively explored how students adapt to different clinical environments. White found that students from a PBL curriculum adapted more effectively and used more SRL skills when transitioning to the clinical environment than students from a traditional curriculum [18]. In Woods et al.'s study, students showed high levels of SRL as they adapted to a surgical rotation but lacked critical self-reflection [10]. Berkhout et al.'s observed in their study that experienced students required less support and were more likely to create their own learning goals compared to novice students [19].

\section{Self-regulated learning and academic achievement}

Five studies reported correlations between levels of SRL and academic achievement during clerkship [20-24]. Sobral's and Song et al.'s studies found associations between aspects of SRL and achievement in written exams during the clinical years [21, 22], whilst Turan and Konan found no such relationship between SRL scores and written examination results [20]. In regard to success in clinical skills three studies found associations [20, 22, 23]. Turan and Konan found weak correlations between SRL scores and Objective Structured Clinical Examination (OSCE) results [20], Sobral found associations between SRL scores and diagnostic skill [22] and Cleary et al. found a link between SRL and success in cannulation [23]. One study found SRL was negatively correlated with procrastination and positively correlated with mastery goal structures, two variables linked with academic success [24].

\section{Self-regulated learning and mental health}

Nguyen et al. [25] observed that most SRL scores were negatively associated with depression.

\section{Factors influencing self-regulated learning levels}

This review found the SRL of medical students can be affected by a wide range of variables [5, 18, 22, 26-28]. Two studies found that experience was linked with higher levels of SRL $[19,26]$. Alegria et al.'s study suggests that technological resources such as tablet computers can further cultivate SRL levels by allowing students to access clinical and educational information [5]. Another study reports that a PBL curriculum can support the SRL of students especially during the transition to the clinical environment [18, 19]. Sobral's study suggests reflection, one aspect of SRL, can be systematically improved through specific interventions [22]. Berkhout et al.'s 2015 study reports the SRL of clinical medical students is influenced by a range of variables including personal, contextual, social factors as well as experienced autonomy [27]. Lyons-Warren et al., suggest SRL is hindered when students feel there is a lack of flexibility when pursuing their learning needs [28]. Berkhout et al.'s 2017 study proposes five SRL patterns exist for clinical students, with each pattern requiring a unique approach to support learning [29].

\section{How has self-regulated learning in medical students in the clinical learning environment been measured?} Methods used to study SRL were varied and included qualitative, quantitative and mixed-method approaches.

Qualitative processes such as semi structured interviews and focus groups were used in five studies $[5,10$, $18,19,27]$. One other study used microanalytic assessment [23]. Microanalysis was originally used to explore the differences in SRL between novice and professional sportsmen [30], and is a structured process which involves verbal responses to open-ended questions, targeting forethought, performance and reflection 


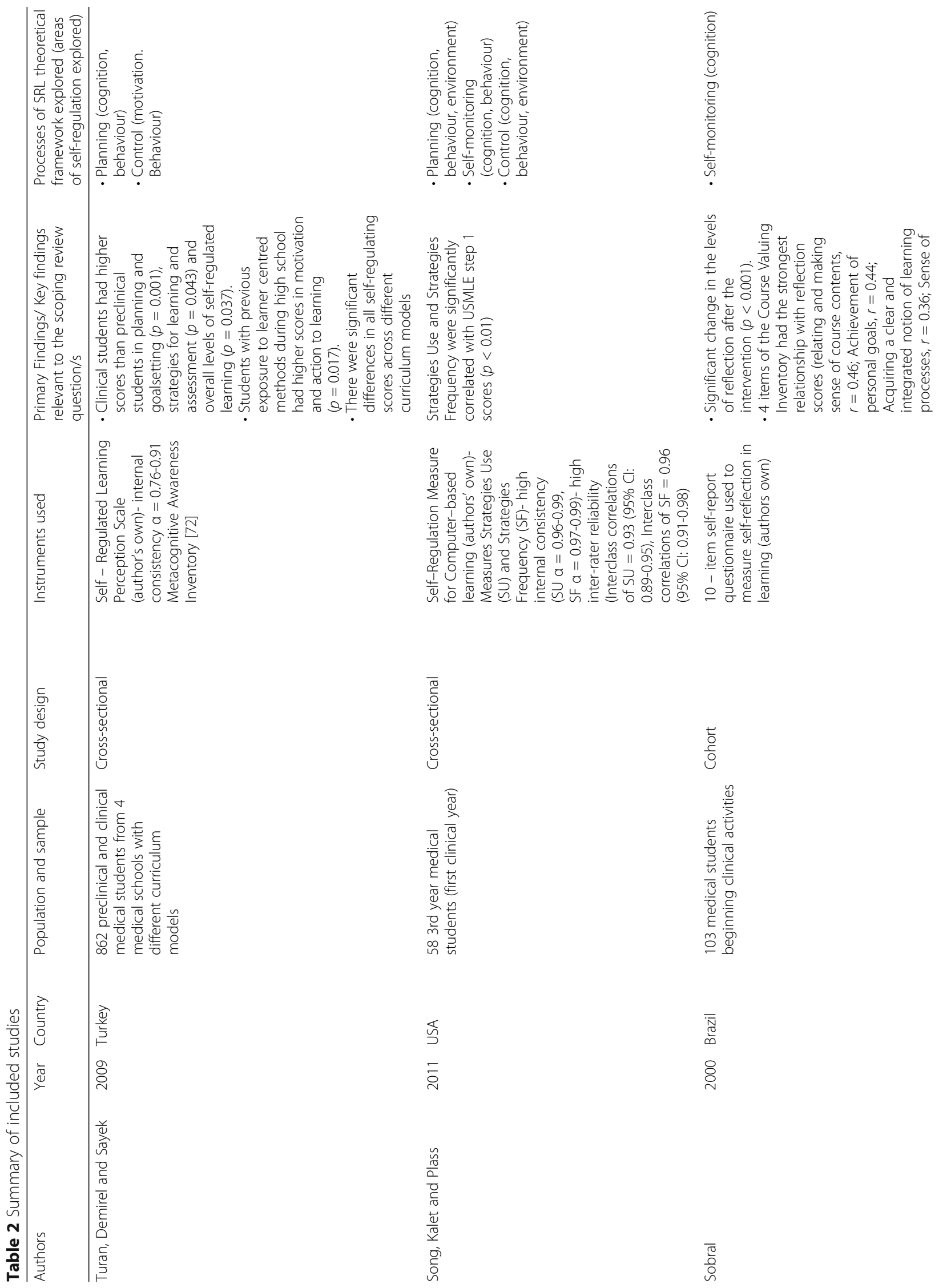



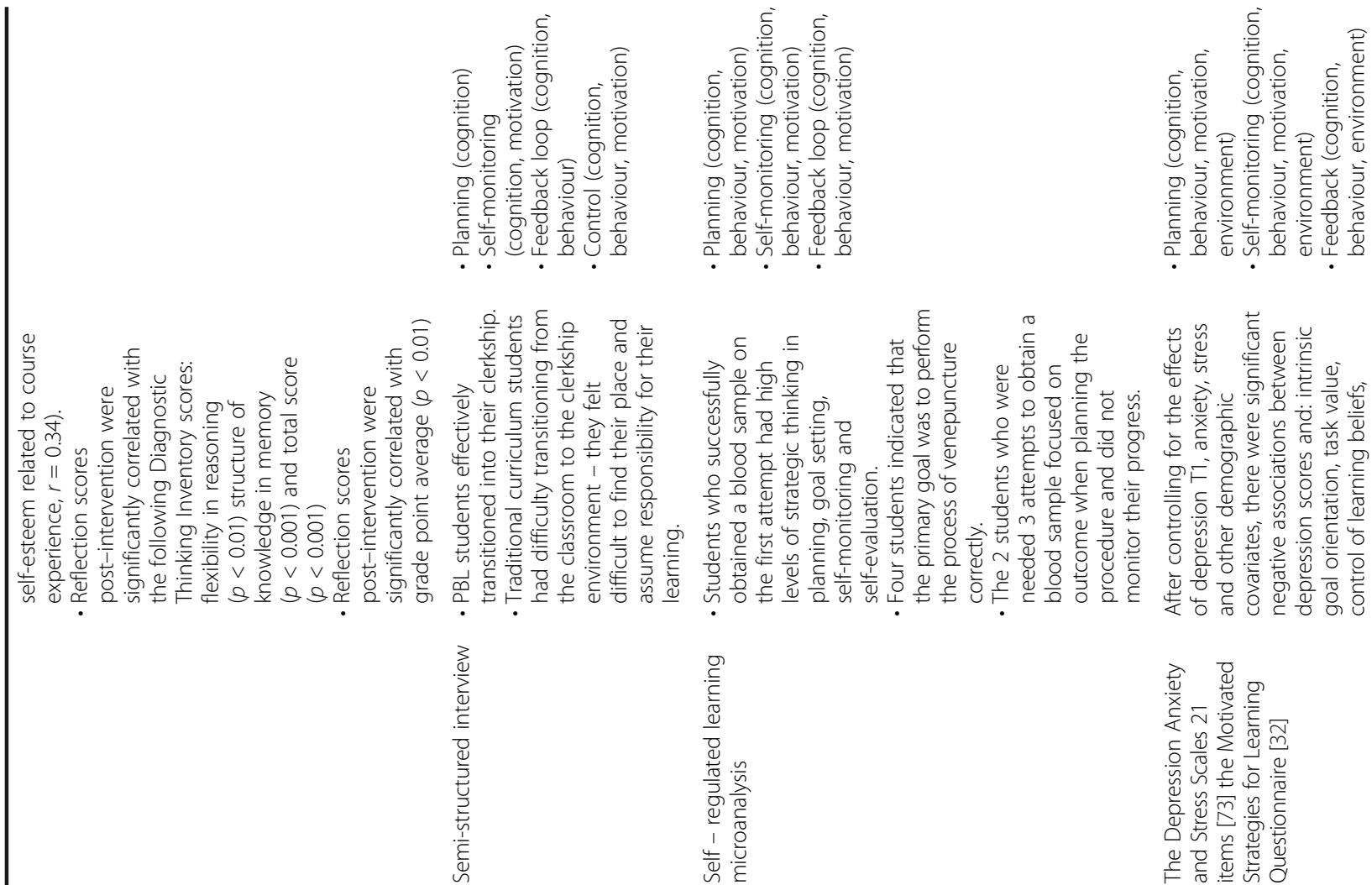

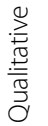

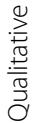

$\frac{5}{0}$
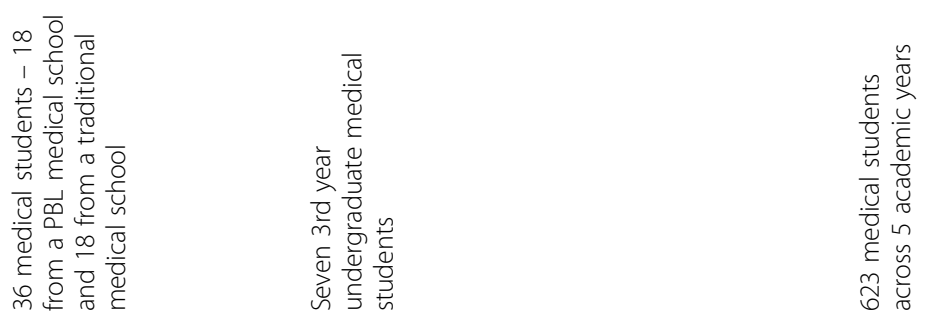

离

芯

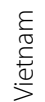

ळे

$\bar{\sigma}$

는

紊

$\frac{n}{0}$
$\frac{0}{0}$
$\frac{0}{0}$
$n$
0
$\frac{0}{0}$
$\frac{\pi}{0}$
$\frac{0}{U}$

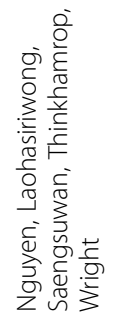




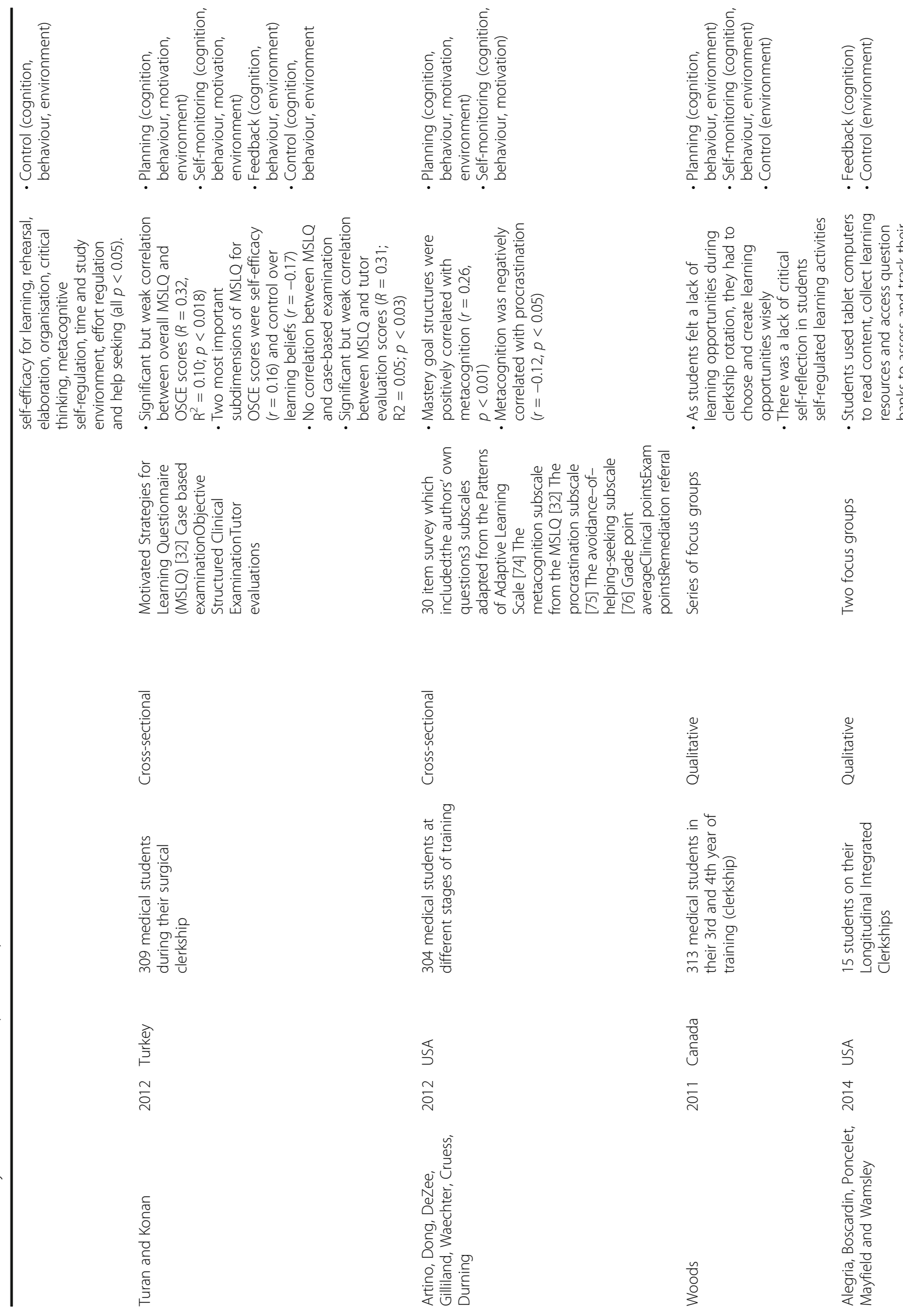



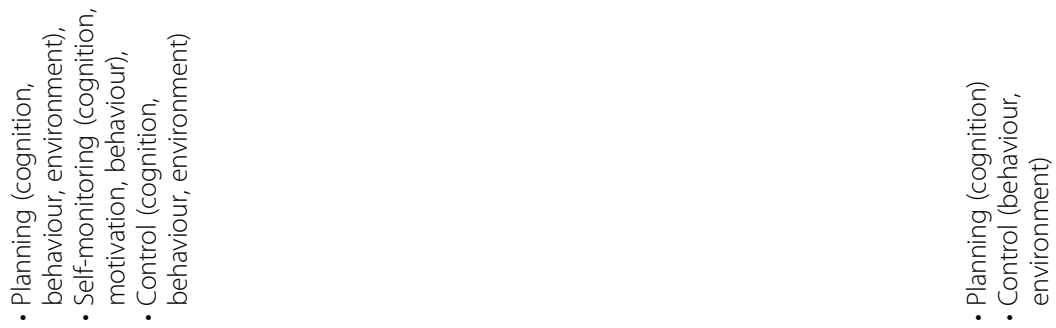

$$
\text { 事 }
$$$$
\text { 응 }
$$

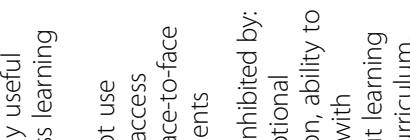

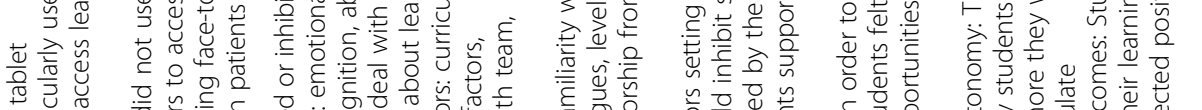

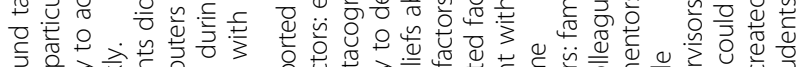

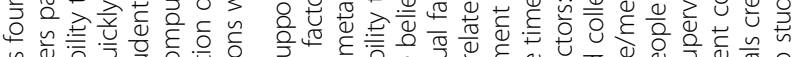

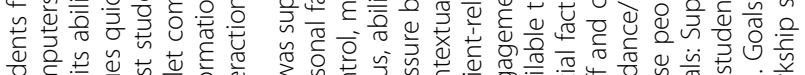

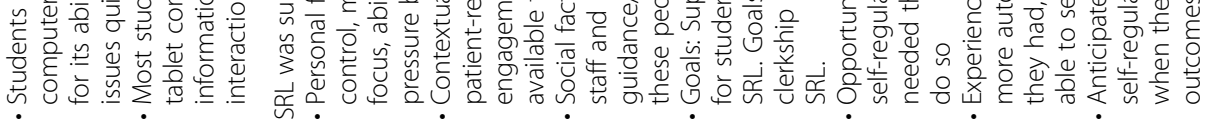

的专

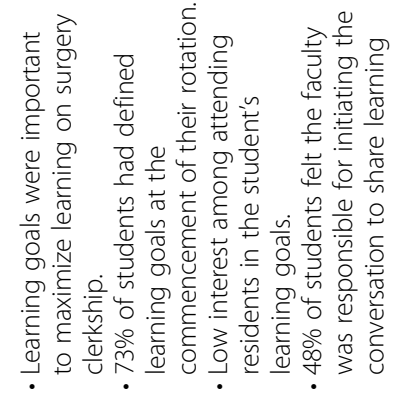
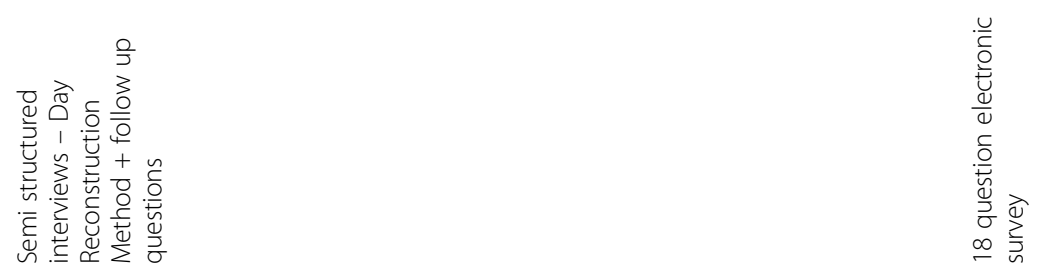

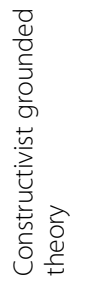
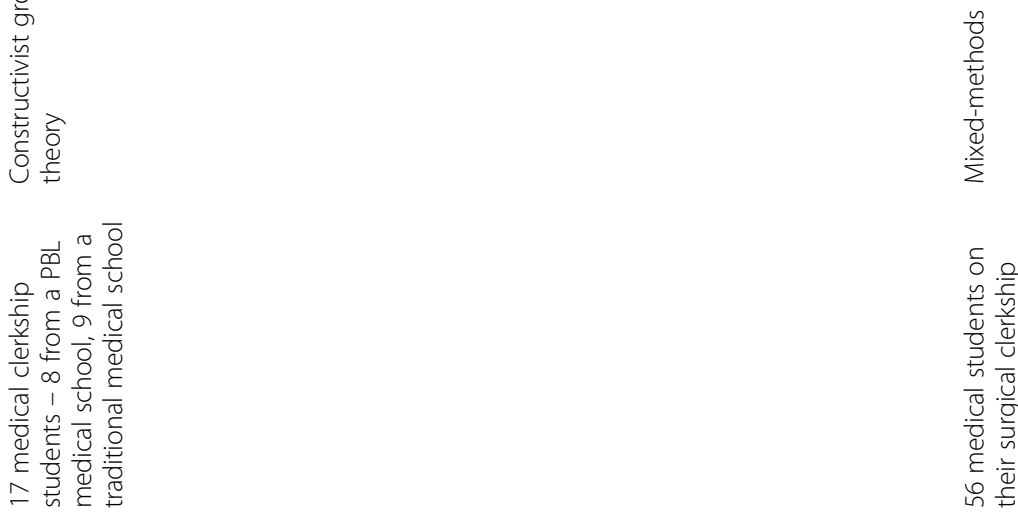

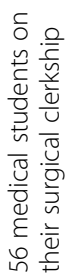

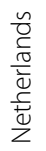

$\stackrel{\sqrt[4]{3}}{s}$

$\stackrel{n}{\grave{n}}$

$\stackrel{2}{\circ}$

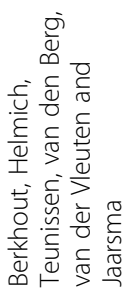



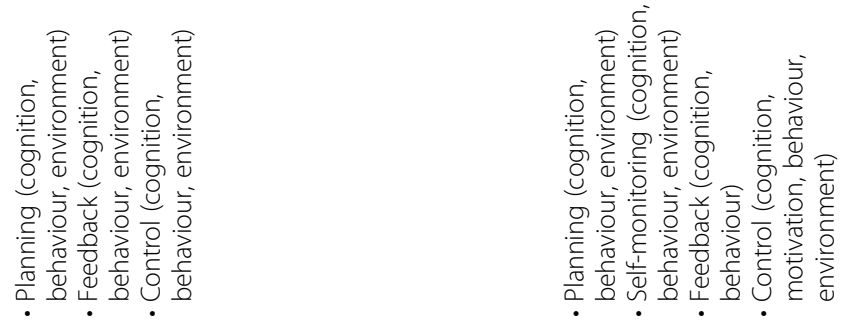

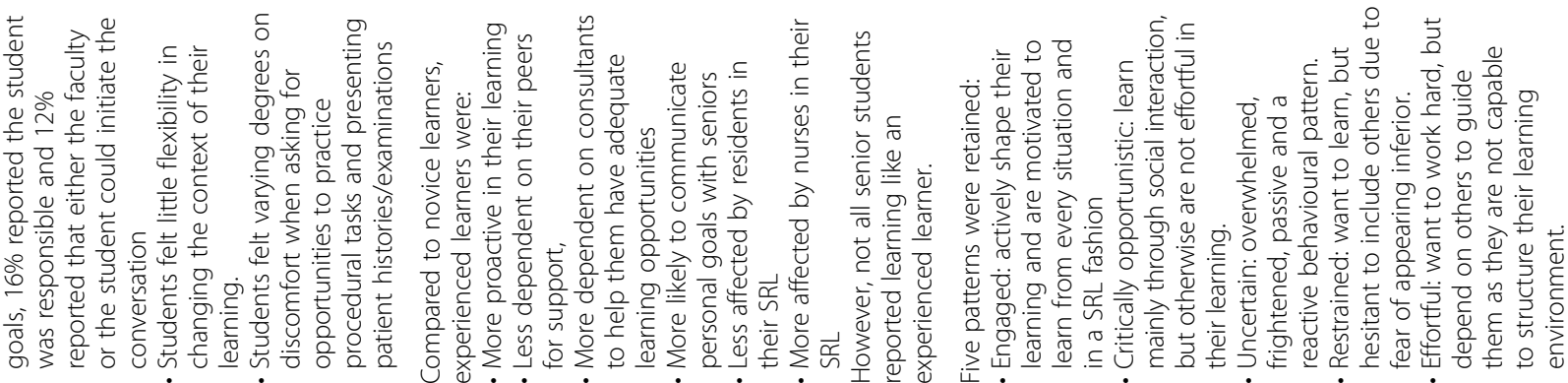

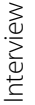

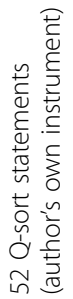

20
0
0
+
0
0
0
0
0
0
0

केे
응
0
ठ
$\frac{1}{0}$
है
0

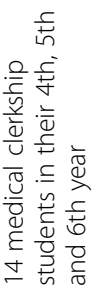

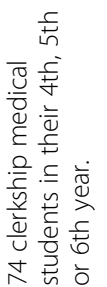

$\frac{n}{0}$
$\frac{1}{4}$
$\frac{0}{d}$
$\frac{1}{2}$
$\frac{0}{Z}$
$\frac{0}{2}$

$\frac{n}{0}$
$\frac{0}{2}$
$\frac{0}{0}$
$\frac{1}{0}$
$\frac{0}{2}$

후
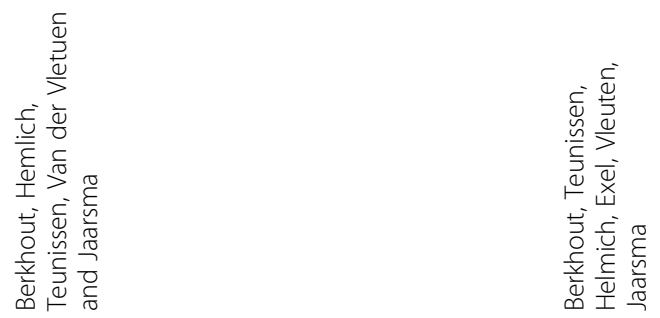
processes during a specific task. The responses are recorded verbatim then coded [31].

Quantitative approaches included the Self-Regulated Learning Measure for Computer-based learning (SRMC) [21], the Self-Regulated Learning Perception Scale [26] and the Motivated Strategies for Learning Questionnaire (MSLQ) or a modified version of this instrument $[20,25]$.

The SRMC tests the use and frequency of 10 SRL subcategories (self-evaluation, organizing and transforming, goal setting and planning, seeking information, keeping records and monitoring, environmental structuring, selfconsequences, rehearsing and memorizing, seeking social assistance, and reviewing records) and two classes of nonself regulation behavior (will power and non-applicable statements). The tool has high internal consistency and high inter-rater reliability [21].

The Self-Regulated Learning Perception Scale uses 41 items to measure 4 domains; 1 ) motivation and action to learning 2) planning and goalsetting 3) strategies for learning and assessment and 4) lack of self-directedness [26]. The scale is highly reliable.

Three articles used the MSLQ [20, 24, 25], which was developed by Pintrich in 1991 [32]. The MSLQ contains 81, 7-point Likert type scale questions measuring 15 subscales of SRL. The MSLQ has variable internal consistency depending on the subscale and high validity [2].

One study used Q-methodology, a method that uses features of both quantitative and qualitative measures [29]. In the Q-methodology participants sort a set of statements along a continuum of a fixed grid (from not at all applicable to me, to very applicable to me) and are asked to explain their rationale for their sorting choices. Similar patterns are identified in the population, and the resulting patterns are interpreted and described as shared perspectives.

\section{Discussion}

In this review, the literature on the SRL of medical students in the clinical environment was systematically searched and summarized. All but three studies [18, 26, 27] were conducted amongst students from a single institution.

\section{Coverage of the SRL theoretical framework by the included studies}

The four processes and four areas of SRL were well covered by the included studies (see Table 3 ). Whilst some studies focussed on explicit parts of SRL such as increasing control of the learner's environment [5], other studies through the use of instruments such as the MSLQ explored SRL through a wider lens [20, 25]. Examining studies outside the SRL literature would be useful to further characterise specific aspects of SRL, for example how clinical medical students have appraised the effectiveness of the clinical learning environment [33, 34].

\section{Changes in self-regulated learning occur in the clinical learning environment}

Two studies that investigated clinical transition highlighted the importance of self-regulating learning to maximise experiential learning $[10,18]$. The importance of self-regulated learning during the transition to clerkship is not surprising as supervisors are often pre-occupied with patient care and sometimes not interested to teach $[35,36]$. However, this scoping review did not find any quantitative studies that explored the preclinical to clinical transition using a validated tool. Thus future studies could explore this transition using a validated quantitative approach to provide further insights into the topic.

Beyond the transition period, Berkhout et al.'s study suggests SRL continues to develop in the clinical environment, with novice and experienced learners having different needs to support their SRL. The study notes that novice students require more support from others, specifically residents and peers, to help them formulate learning goals and navigate the new learning environment. In the broader medical education literature, the significance of resident teaching is mixed, with some studies highlighting the correlation between resident teaching and medical student learning [37] and academic performance [38], whilst other studies not finding such an effect $[39,40]$.

\section{Self-regulated learning, academic achievement and mental health}

This review indicates that higher levels of SRL may be beneficial for medical students due to its positive correlation with academic achievement and clinical skills [20-24] as well as its negative association with depression [25].

The positive correlation between SRL and diagnostic and clinical skills is important for students not just when they are in medical school but also as practising physicians. Furthermore, as doctors must maintain their competencies and skills throughout their careers in order to consistently meet the high standards of patient care [41-43], they must develop an awareness of their learning needs and use appropriate learning strategies to achieve their goals. As lifelong learners, doctors should adopt SRL and be motivationally, behaviourally and meta-cognitively proactive in their own learning process [44-46]. Developing SRL in medical students in the clinical environment is important not only for the short term, so that medical students may achieve better grades and clinical proficiency, but also for the long-term so that graduates can participate in lifelong learning and provide patients with effective care. 


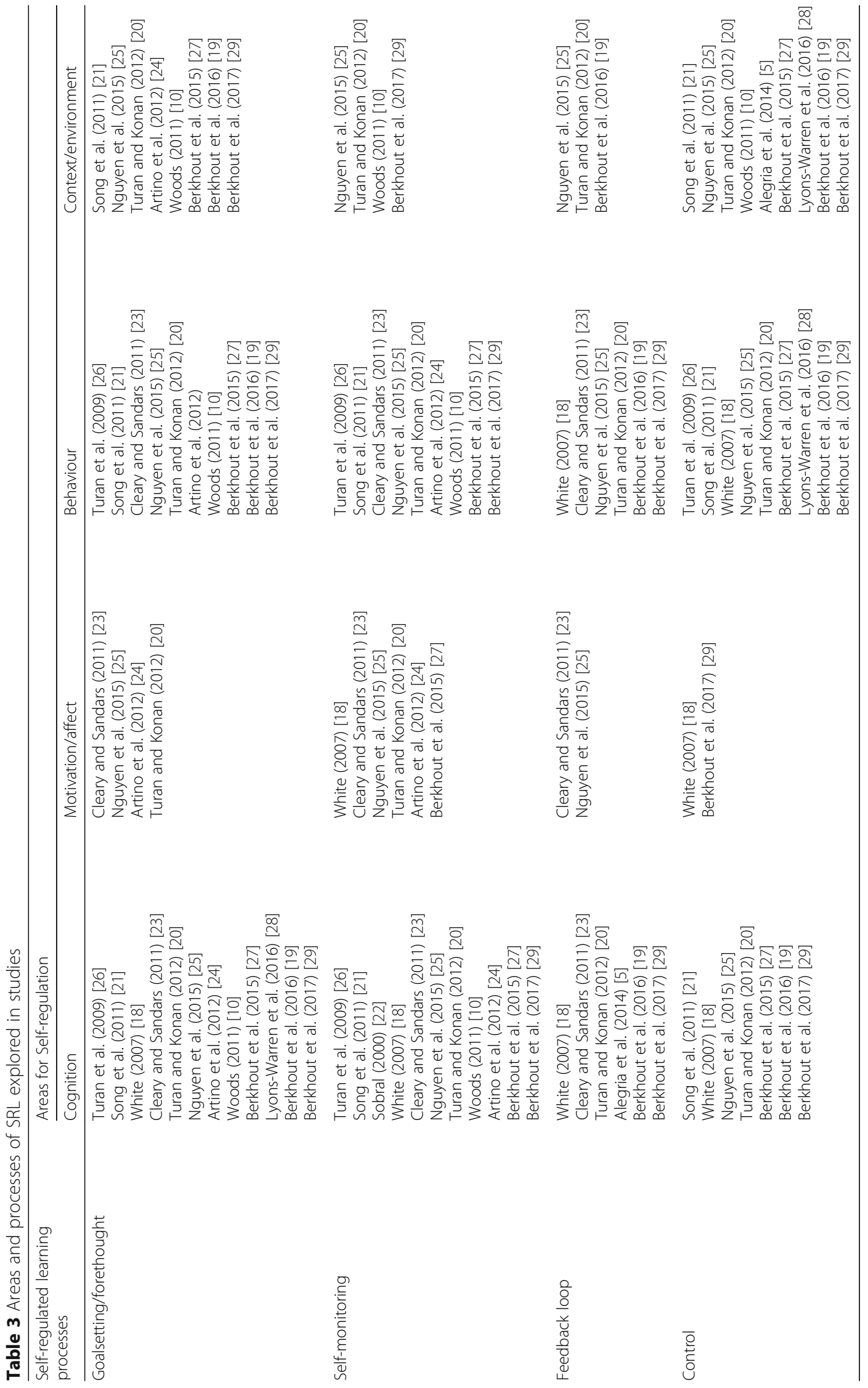


The negative association between SRL and depression is significant because medical students as a whole face higher levels of psychological stress than the general population $[47,48]$, with studies suggesting that rates of depression increase during the clinical years [49, 50]. Moreover some evidence suggests that mental distress during medical school is associated with problems as physicians [51, 52], which might negatively affect patient care [53]. Although the link between SRL and decreased depression is correlational and not causative, the association between aspects of SRL and mental health has been found in other studies involving preclinical medical students [54] as well as in studies outside medical education $[55,56]$. Thus it is may be relevant to promote SRL strategies to help students optimise their mental well-being.

\section{What factors influence the self-regulated learning levels} of medical students in the clinical learning environment? In their study, Turan et al. found that medical students in the clinical years appeared to intrinsically have higher levels of SRL than preclinical medical students [26]. Although it is reassuring to believe self-regulating learning naturally develops and increases as students progress through medical school and postgraduate training, caution must applied when interpreting the results as the study explored the changes in SRL in separate cohorts rather than following its development in the same student cohort. Indeed numerous authors in the broader literature have suggested that self-regulated learners are not always successful when left to develop their own strategies [57-60].

Finally it appears that at least some aspects of SRL can be targeted and improved, with one study suggesting that levels of reflection in students can be increased after an intervention. This finding that SRL can be improved by certain interventions is supported by research outside the transitions literature [42, 61-63], with one author suggesting that explicitly teaching metacognition is efficacious [61].

\section{How has self-regulated learning in medical students in the clinical learning environment been measured?}

Several approaches have been used to measure SRL in clinical medical students and there appears to be no single best approach with each approach having its advantages and disadvantages. For example, studies using the qualitative approach were effective in identifying and exploring contextual factors related to SRL in the clinical environment whereas the quantitative approach could identify the strengths of associations to test hypotheses. Two of the three studies using quantitative methods developed their own instruments specifically for use in the clinical context $[21,26]$. In terms of microanalytic assessment, the tool has been reported in the literature to be effective in examining motor and cognitive skills that have a clear beginning, middle and end section [64]. Thus microanalytic assessment appears to be a suitable method to analyse the SRL of students during specific tasks such as taking a history and examining a patient or skills such as cannulation, but not to measure global SRL that may occur with informal learning in the clinical environment. Q methodology measures subjective experiences through features of qualitative and quantitative approaches, and has been reported to be a more robust technique than Likert-type scales to study attitudes in health education [65].

Studies which investigated SRL across multiple cohorts reported the cross-sectional design as a limitation. These authors suggest longitudinal studies may allow the transition to be better measured. Studies using questionnaires as their collection tool reported reliability and validity limitations, especially as they measured self-reported learning behaviours, which are subject to social desirability and recall bias. However each survey instrument had reasonable psychometric properties. Some studies also reported the possibility of selection bias either due to small sample sizes [24] or due to inherent differences in the selected students [18]. Future studies could thus consider using longitudinal study design using a range of methods to better understand how SRL develops and is maintained in the clinical environment.

Not identified in our search were novel qualitative methods used in the broader SRL literature, such as think-aloud protocols [66, 67], video-taped events [68], structured study-diaries [69] and computer trace analysis $[70,71]$. Future studies could use these novel methods to measure the SRL of clinical medical students.

\section{Limitations}

This review was restricted to articles published in the English language and those concerning the medical profession. We also did not include studies with similar terms to SRL such as self-directed learning in our review due to conceptual differences in perspectives and constructs. We did include medical and educational databases as well as Google Scholar to widen the search to where SRL research might be catalogued. Future research should consider including nursing and other allied health professionals as learning in the clinical environment is also a core part of health professional education and findings about effective learning could be transferrable across professions. As this article is a scoping review and not a systematic review, we did not critically appraise the selected studies. We did however locate findings which addressed our aims of examining the nature and extent of the literature, and to identify potential future research directions. 


\section{Conclusion}

We explored what is known about medical students in the clinical environment, specifically in relation with SRL. We found several relevant papers, with most published in the last 5 years, suggesting a growing interest in SRL in the clinical environment in medical education. Although most had a cross-sectional or qualitative design, quantitative approaches may yield complementary insights, with longitudinal research being needed to examine how SRL develops and is maintained in clinical learning environments. Additionally future studies could consider using novel qualitative methods to explore the SRL of medical students in the clinical environment.

\section{Abbreviations \\ MSLQ: Motivated Strategies for Learning Questionnaire; OSCE: Objective Structured Clinical Examination; PBL: Problem-Based Learning; SRL: Self-regulated learning; SRMC: Self-regulated Learning Measure for Computer-based Learning}

\section{Acknowledgements}

Not applicable.

\section{Funding}

This project was supported by a 2014 Western Sydney University Summer Research Scholarship, but the scholarship had no influence on the design, collection, analysis or interpretation of the results, nor in the writing of the manuscript.

\section{Availability of data and materials}

Not applicable.

\section{Authors' contributions}

KC, BM, VL and WH co-designed the search strategy. All authors developed the data extraction form. KC conducted the database search, screened the resulting articles and was primarily responsible for writing the manuscript. All authors reviewed, edited and approved the final manuscript.

\section{Ethics approval and consent to participate}

Not applicable.

\section{Consent for publication}

Not applicable.

\section{Competing interests}

The authors declare that they have no competing interests.

\section{Publisher's Note}

Springer Nature remains neutral with regard to jurisdictional claims in published maps and institutional affiliations.

Received: 9 September 2016 Accepted: 27 June 2017

Published online: 10 July 2017

\section{References}

1. Zimmerman BJ, Pons MM. Development of a structured interview for assessing student use of self-regulated learning strategies. Am Educ Res J. 1986;23(4):614-28

2. Pintrich PR, Smith DA, García T, McKeachie WJ. Reliability and predictive validity of the motivated strategies for learning questionnaire (MSLQ). Educ Psychol Meas. 1993;53(3):801-13.

3. Boekaerts M. Self-regulated learning: a new concept embraced by researchers, policy makers, educators, teachers, and students. Learn Instr. 1997;7(2):161-86.

4. Pintrich PR, De Groot EV. Motivational and self-regulated learning components of classroom academic performance. J Educ Psychol. 1990; 82(1):33.
5. Alegría DAH, Boscardin C, Poncelet A, Mayfield C, Wamsley M. Using tablets to support self-regulated learning in a longitudinal integrated clerkship. Med Educ Online. 2014;19(1):23638

6. Pintrich PR. A conceptual framework for assessing motivation and selfregulated learning in college students. Educ Psychol Rev. 2004;16(4): 385-407.

7. Artino AR, Brydges R, Gruppen LD. Self-regulated learning in healthcare profession education: theoretical perspectives and research methods. 1st ed. Oxford: JohnWiley \& Sons, Ltd; 2015.

8. Zimmerman BJ. A social cognitive view of self-regulated academic learning. J Educ Psychol. 1989;81(3):329

9. Cartier S, Plante A, Tardif J. Learning by reading: description of learning strategies of students involved in a problem-based learning program. 2001. (ERIC document reproduction service no. ED 452 511).

10. Woods NN, Mylopoulos M, Brydges R. Informal self-regulated learning on a surgical rotation: uncovering student experiences in context. Adv Health Sci Educ. 2011:16(5):643-53.

11. Eva KW, Regehr G. Self-assessment in the health professions: a reformulation and research agenda. Acad Med. 2005;80(10):S46-54.

12. Davis K, Drey N, Gould D. What are scoping studies? A review of the nursing literature. Int J Nurs St. 2009;46(10):1386-400.

13. Pham MT, Rajić A, Greig JD, Sargeant JM, Papadopoulos A, McEwen SA. A scoping review of scoping reviews: advancing the approach and enhancing the consistency. Res Synth Methods. 2014;5(4):371-85.

14. Arksey H, O'Malley L. Scoping studies: towards a methodological framework. Int J Soc Res Method. 2005;8(1):19-32

15. Armstrong R, Hall BJ, Doyle J, Waters E. 'scoping the scope'of a cochrane review. J Public Health. 2011;33(1):147-50.

16. Loyens SM, Magda J, Rikers RM. Self-directed learning in problem-based learning and its relationships with self-regulated learning. Educ Psychol Rev. 2008;20(4):411-27

17. Saks K, Leijen Ä. Distinguishing self-directed and self-regulated learning and measuring them in the E-learning context. Procd Soc Behv. 2014;112:190-8.

18. White CB. Smoothing out transitions: how pedagogy influences medical students' achievement of self-regulated learning goals. Adv Health Sci Educ. 2007:12(3):279-97.

19. Berkhout JJ, Helmich E, Teunissen PW, Vleuten CP, ADC J. How clinical medical students perceive others to influence their self-regulated learning. Med Educ. 2016;51(3):269-79.

20. Turan S, Konan A. Self-regulated learning strategies used in surgical clerkship and the relationship with clinical achievement. J Surg Educ. 2012; 69(2):218-25.

21. Song HS, Kalet AL, Plass JL. Assessing medical students' self-regulation as aptitude in computer-based learning. Adv Health Sci Educ. 2011;16(1):97-107.

22. Sobral DT. An appraisal of medical students' reflection-in-learning. Med Educ. 2000;34(3):182-7.

23. Cleary TJ, Sandars J. Assessing self-regulatory processes during clinical skill performance: a pilot study. Med Teach. 2011;33(7):e368-e74.

24. Artino AR Jr, Dong T, DeZee KJ, Gilliland WR, Waechter DM, Cruess D, et al. Achievement goal structures and self-regulated learning: relationships and changes in medical school. Acad Med. 2012;87(10):1375-81.

25. Van Nguyen H, Laohasiriwong W, Saengsuwan J, Thinkhamrop B, Wright P. The relationships between the use of self-regulated learning strategies and depression among medical students: an accelerated prospective cohort study. Psychol Health Med. 2015:20(1):59-70.

26. Turan S, Demirel Ö, Sayek I. Metacognitive awareness and self-regulated learning skills of medical students in different medical curricula. Med Teach. 2009;31(10):e477-e83.

27. Berkhout JJ, Helmich E, Teunissen PW, Berg JW, Vleuten CPM, Jaarsma ADC. Exploring the factors influencing clinical students' self-regulated learning. Med Educ. 2015;49(6):589-600.

28. Lyons-Warren AM, Kirby JP, Larsen DP. Student views on the role of selfregulated learning in a surgery clerkship. J Surg Res. 2016;206(2):273-9.

29. Berkhout J, Teunissen $P$, Helmich $E$, van Exel J, van der Vleuten $C$, Jaarsma D, et al. Patterns in clinical students' self-regulated learning behavior: a Qmethodology study. Adv Health Sci Educ. 2017;22(1):105-21.

30. Cleary TJ, Zimmerman BJ. Self-regulation differences during athletic practice by experts, non-experts, and novices. J Appl Sport Psychol. 2001;13(2):185-206.

31. Artino AR Jr, Cleary TJ, Dong T, Hemmer PA, Durning SJ. Exploring clinical reasoning in novices: a self-regulated learning microanalytic approach. Med Educ. 2014;48(3):280-91. 
32. Pintrich PR. A manual for the use of the motivated strategies for learning questionnaire (MSLQ). 1991.

33. Daelmans H, Hoogenboom R, Donker A, Scherpbier A, Stehouwer C, Van der Vleuten $\mathrm{C}$. Effectiveness of clinical rotations as a learning environment for achieving competences. Med Teach. 2004;26(4):305-12.

34. Torre DM, Sebastian JL, Simpson DE. Learning activities and high-quality teaching: perceptions of third-year IM clerkship students. Acad Med. 2003; 78(8):812-4.

35. Dolmans D, Wolfhagen I, Heineman E, Scherpbier A. Factors adversely affecting student learning in the clinical learning environment: a student perspective. Educ Health. 2008;21(3):32.

36. Irby DM, Bowen JL. Time-efficient strategies for learning and performance. Clin Teach. 2004;1(1):23-8.

37. Roop SA, Pangaro L. Effect of clinical teaching on student performance during a medicine clerkship1. Am J Med. 2001;110(3):205-9.

38. Griffith CH 3rd, Wilson JF, Haist SA, Ramsbottom-Lucier M. Do students who work with better housestaff in their medicine clerkships learn more? Acad Med J Assoc Am Med Coll. 1998;73(10 Suppl):S57-9.

39. Hill AG, Srinivasa S, Hawken SJ, Barrow M, Farrell SE, Hattie J, et al. Impact of a resident-as-teacher workshop on teaching behavior of interns and learning outcomes of medical students. J Grad Med Educ. 2012;4(1):34-41.

40. Stern DT, Williams BC, Gill A, Gruppen LD, Woolliscroft JO, Grum CM. Is there a relationship between attending physicians' and residents' teaching skills and students' examination scores? Acad Med. 2000;75(11):1144-6.

41. Lucieer SM, Jonker L, Visscher C, Rikers RMJP, Themmen APN. Self-regulated learning and academic performance in medical education. Med Teach. 2016:38(6):585-93.

42. Brydges R, Butler D. A reflective analysis of medical education research on self-regulation in learning and practice. Med Educ. 2012;46(1):71-9.

43. Greveson GC, Spencer JA. Self-directed learning-the importance of concepts and contexts. Med Educ. 2005;39(4):348-9.

44. Zimmerman BJ. Becoming a self-regulated learner: which are the key subprocesses? Contemp Educ Psychol. 1986;11(4):307-13.

45. Quirk M. Intuition and metacognition in medical education: keys to developing expertise: Springer publishing company; 2006.

46. Schraw G, Crippen KJ, Hartley K. Promoting self-regulation in science education: Metacognition as part of a broader perspective on learning. Res Sci Educ. 2006;36(1-2):111-39.

47. Henning K, Ey S, Shaw D. Perfectionism, the impostor phenomenon and psychological adjustment in medical, dental, nursing and pharmacy students. Med Educ. 1998;32(5):456-64.

48. Dyrbye LN, Thomas MR, Shanafelt TD. Systematic review of depression, anxiety, and other indicators of psychological distress among US and Canadian medical students. Acad Med. 2006;81(4):354-73.

49. Goldin SB, Wahi MM, Faroog OS, Borgman HA, Carpenter HL, Wiegand LR, et al. Student quality-of-life declines during third year surgical clerkship. J Surg Res. 2007;143(1):151-7.

50. Ludwig AB, Burton W, Weingarten J, Milan F, Myers DC, Kligler B. Depression and stress amongst undergraduate medical students. BMC Med Educ. 2015;15:141.

51. Firth-Cozens J. Individual and organizational predictors of depression in general practitioners. Brit J Gen Pract. 1998;48(435):1647-51.

52. Tyssen R, Vaglum P, Gronvold NT, Ekeberg O. Factors in medical school that predict postgraduate mental health problems in need of treatment. A nationwide and longitudinal study. Med Educ. 2001;35(2):110-20.

53. Firth-Cozens J, Greenhalgh J. Doctors' perceptions of the links between stress and lowered clinical care. Soc Sci Med. (1982) 1997;44(7):1017-1022.

54. Artino AR Jr, Hemmer PA, Durning SJ. Using self-regulated learning theory to understand the beliefs, emotions, and behaviors of struggling medical students. Acad Med J Assoc Am Med Coll. 2011;86(10 Suppl):S35-8.

55. Bandura A. Social cognitive theory: an agentic perspective. Annu Rev Psychol. 2001;52(1):1-26.

56. Ghaderi A, Salehi M. A study of the level of self-efficacy, depression and anxiety between accounting and management students: Iranian evidence. World Appl Sci. 2011;12(9):1299-306.

57. Kornell N, Bjork RA. The promise and perils of self-regulated study. Psychon B Rev. 2007;14(2):219-24

58. Kornell N, Bjork RA. Optimising self-regulated study: the benefits-and costs—of dropping flashcards. Memory. 2008;16(2):125-36.

59. Kruger J, Dunning D. Unskilled and unaware of it: how difficulties in recognizing one's own incompetence lead to inflated self-assessments. J Pers Soc Psychol. 1999;77(6):1121.
60. Hodges B, Regehr G, Martin D. Difficulties in recognizing one's own incompetence: novice physicians who are unskilled and unaware of it. Acad Med. 2001;76(10):S87-S9.

61. Tanner KD. Promoting student metacognition. CBE-Life Sci Educ. 2012; 11(2):113-20.

62. Sandars J. Pause 2 learn: developing self-regulated learning. Med Educ. 2010;44(11):1122-3.

63. Zimmerman BJ. Attaining self-regulation: a social cognitive perspective. Handb Self Regul. 2000;13(1):695-716.

64. Cleary T. Emergence of self-regulated learning microanalysis. Handb Self Regul Learn Perform. 2011:329-45.

65. Cross RM. Exploring attitudes: the case for Q methodology. Health Educ Res. 2005:20(2):206-13.

66. Azevedo R, Cromley JG. Does training on self-regulated learning facilitate students' learning with hypermedia? J Educ Psychol. 2004;96(3):523.

67. Azevedo R, Cromley JG, Seibert D. Does adaptive scaffolding facilitate students' ability to regulate their learning with hypermedia? Contemp Educ Psychol. 2004;29(3):344-70.

68. Whitebread D, Coltman P, Pasternak DP, Sangster C, Grau V, Bingham S, et al. The development of two observational tools for assessing metacognition and self-regulated learning in young children. Metacogn Learn. 2009:4(1):63-85.

69. Schmitz B, Wiese BS. New perspectives for the evaluation of training sessions in self-regulated learning: time-series analyses of diary data. Contemp Educ Psychol. 2006;31(1):64-96.

70. Winne PH, Nesbit JC, Kumar V, Hadwin AF, Lajoie SP, Azevedo R, et al. Supporting self-regulated learning with gStudy software: the learning kit project. Technol Instr Cogn Learn. 2006;3(1/2):105.

71. Winne PH, Jamieson-Noel D. Exploring students' calibration of self reports about study tactics and achievement. Contemp Educ Psychol. 2002;27(4): 551-72.

72. Schraw G, Dennison RS. Assessing metacognitive awareness. Contemp Educ Psychol. 1994;19(4):460-75.

73. Lovibond PF, Lovibond SH. The structure of negative emotional states: comparison of the depression anxiety stress scales (DASS) with the Beck depression and anxiety inventories. Behav Res Ther. 1995;33(3):335-43.

74. Midgley C, Maehr ML, Hruda LZ, Anderman E, Anderman L, Freeman KE, et al. Manual for the patterns of adaptive learning scales. Ann Arbor. 2000; 1001:48109-1259.

75. Wolters CA. Understanding procrastination from a self-regulated learning perspective. J Educ Psychol. 2003;95(1):179.

76. Pajares F, Cheong YF, Oberman P. Psychometric analysis of computer science help-seeking scales. Educ Psychol Meas. 2004;64(3):496-513.

\section{Submit your next manuscript to BioMed Central and we will help you at every step:}

- We accept pre-submission inquiries

- Our selector tool helps you to find the most relevant journal

- We provide round the clock customer support

- Convenient online submission

- Thorough peer review

- Inclusion in PubMed and all major indexing services

- Maximum visibility for your research

Submit your manuscript at www.biomedcentral.com/submit 